\title{
The in vitro Efficacy of Betadine Antiseptic Solution and Colloidal Silver Gel Combination in Inhibiting the
}

\section{Growth of Bacterial Biofilms}

\author{
Phat Tran' ${ }^{1}$, Keaton Luth ${ }^{2}$, Huy Dong ${ }^{3}$, Ameesh Dev ${ }^{4}$, Dilip Mehta ${ }^{5}$, Kelly Mitchell ${ }^{6}$, K.W. Moeller ${ }^{7}$; C. \\ D. Moeller ${ }^{8}$, Ted Reid",** \\ 1. Texas Tech University Health Sciences Center, Lubbock Texas 79430; Phat.Tran@ttuhsc.edu \\ 2. Texas Tech University Health Sciences Center, Lubbock Texas 79430; keaton.luth@gmail.com \\ 3. Texas Tech University Health Sciences Center, Lubbock Texas 79430; huy.t.dong@uth.tmc.edu \\ 4. Texas Tech University Health Sciences Center, Lubbock Texas 79430; deva@livemail.uthscsa.edu \\ 5. Viridis BioPharma Pvt. Ltd. Mumbai, India; viridis@ vsnl.com \\ 6. Texas Tech University Health Sciences Center, Lubbock Texas 79430; kelly.mitchell@ttuhsc.edu \\ 7. American Biotech Labs LLC, Alpine, Utah; keith@ablsilver.com \\ 8. American Biotech Labs LLC, Alpine, Utah; cam@ablsilver.com \\ 9. Texas Tech University Health Sciences Center, Lubbock Texas 79430; ted.reid@ttuhsc.edu \\ * Correspondence: ted.reid@ttuhsc.edu Tel.: 806-743-9982
}

\begin{abstract}
Betadine (Providone-Iodine) solution is a topically applied antiseptic, which has been used for wound care and surgery for decades for the prevention and treatment of skin and wound infections. However, several studies have documented the ineffectiveness of Betadine solution. Other topical antimicrobial dressings, including those that contain silver, have been used in the management of infected wounds. The present study was undertaken to determine if the combination of 5\% Betadine solutions and silver colloidal gel (Ag-gel), is more effective than the individual materials in inhibiting the growth of both Gram negative and Gram positive bacteria. These determinations were carried out by both the colony forming unit (CFU) assay, and confocal laser scanning microscopy (CLSM). Ag-gel showed complete inhibition on all the bacteria, except Klebsiella pneumoniae CI strain while 5\% Betadine concentrations did not completely kill any of the tested bacteria. However, $K$. pneumoniae was completely eliminated in the presence of the combination of 5\% Betadine solution plus Ag-gel. Confocal laser microscopy confirmed the CFU results. Thus this study demonstrated that while the individual treatments are not effective in killing all the bacteria tested, the combination of 5\% Betadine solution and Ag-gel completely kill all bacteria tested, including $K$. penumoniae $\mathrm{CI}$.
\end{abstract}

Keywords: Biofilm; Silver Gel; Betadine; Providone-Iodine; Antimicrobial

\section{Introduction}

Wound infections are a serious problem [1-4], and antiseptics have commonly been used on wounds to prevent or treat infection. Among the current antiseptics, Betadine (Providone-iodide) is a broad spectrum antiseptic for topical application in the treatment and prevention of infection in wounds [5-9]. Currently, it is generally accepted to use $5 \%$ betadine solutions for preparation of different surfaces such as in wound preparation $[5,10,11]$. The reason concentrations below $5 \%$ are not used is because it has been shown that concentrations below $5 \%$ are not effective bactericidal agents $[10,12,13]$. Moreover, it is commonly used as a surgical scrub and is applied pre- and post-op to surgical sites $[6,8,9,14]$. 
Topical antimicrobial dressings, including those that contain silver, have long been used to assist with management of infected wounds and those at risk of infection in a wide range of wounds. Silver containing dressings (Silvazine ${ }^{\mathrm{TM}}$, Aquacel $\mathrm{Ag}^{\mathrm{TM}}$, and Acticoat ${ }^{\mathrm{TM}}$ ) studied so far have shown promise in the control of wound infections in human patients $[15,16]$. In vitro studies have shown that silver can kill Gram positive and Gram negative bacteria, in addition to Methicillin Resistant S. aureus and Vancomycin Resistant Enterococci ([17-19].

Because antimicrobial efficacy of Betadine is controversial, the present study was undertaken to measure the effectiveness of $5 \%$ Betadine solution by itself and in combination of silver colloidal gel in inhibiting the growth of both Gram negative and Gram positive bacteria. The silver colloidal gel (Ag-gel) is silver in the $\mathrm{Ag}^{\mathrm{o}}$ form, which doesn't react with the iodide in the Betadine.

\section{Experimental Section}

\section{Providone-Iodide solution preparation}

Ten \% Providone-Iodide or Betadine topical solution (\#NDC-67618-150-04, Betadine Microbicides, Purdue Products LP, Stanford, CT, USA) was purchased from Betadine Microbicides. Betadine solution was diluted to $5 \%$ in sterile $1 \mathrm{X}$ PBS $(\mathrm{pH}=7.4)$. The solution was stored at room temperature until use.

\section{Silver dressing.}

The dressing evaluated contained colloidal silver $\left(\mathrm{Ag}^{\circ}\right)$ in a gel form (Ag-gel). The $\mathrm{Ag}$-gel was obtained from Viridis Biopharma Pvt., Ltd, Mumbai, India. It was tested as $50 \mathrm{mg}$ evenly spread on a $6 \mathrm{~mm}$ diameter BBL blank paper discs (\#B31039, Fisher Scientific, Waltham, MA, USA).

\section{Bacterial strains, media, and growth conditions}

The laboratory strains of bacteria tested were Staphylococcus aureus GFP strain AH133 [20] and Pseudomonas aeruginosa PAO1 GFP strain MM294 [21], which constitutively expresses green fluorescent protein from plasmids pCM11 and pMRP9-1 respectively. These were used for all studies. The strains were routinely grown in Luria-Bertani (LB) broth at $37^{\circ} \mathrm{C}$, with shaking (250 rpm). To maintain pCM11 in AH133, Luria Broth (LB) was supplemented with $1 \mu \mathrm{g} / \mathrm{mL}$ erythromycin. To maintain pMRP9-1 in PAO1, Luria Broth (LB) was supplemented with $300 \mu \mathrm{g} / \mathrm{ml}$ carbenicillin. In addition, clinical isolates of the following bacteria were studied: Klebsiella penumoniae (K. penumoniae CI), Staphylococcus epidermidis (S. epidermidis CI), and Methicillin-resistant Staphylococcus aureus (MRSA CI). The efficacy of 5\% Betadine solution, Ag-gel, and combination of 5\% Betadine solution with Ag-gel was examined using LB medium (\#113002022, MP Biomedicals, Solon, OH) and LB-Agar medium (\#113002222, MP Biomedicals, Solon, $\mathrm{OH}, \mathrm{USA}$ ) as the growth medium. The clinical isolates were obtained from the Clinical lab at Texas Tech University Health Sciences Center under an approved Institutional Review Board protocol, Texas Tech University Medical center/Lubbock, Texas, USA.

\section{Colony forming unit assay}

We analyzed the remaining of bacteria on the discs using the Colony Forming Unit (CFU) assay [22]. The CFU assay is well-standardized, reliable susceptibility testing techniques. Briefly, bacteria were grown overnight in LB medium. The following day, the bacterial culture was washed in Mueller Hinton (MH) broth (\#70192, Sigma-Aldrich, St. Louis, MO, USA), and the bacterial suspension was adjusted to an OD 600 of 0.5 in $\mathrm{MH}$ broth according to the standard guidelines of the National Committee for Clinical Laboratory Standards [23-25]. Following this, a sterile cotton swap was dipped into the adjusted bacterial culture, and a lawn of bacteria was made on a LB Agar plate using the dipped swab The bacteria was then allowed to grow and form a biofilm for 24 hours at $37^{\circ} \mathrm{C}$. The Betadine discs were prepared by adding $20 \mu \mathrm{l}$ of $5 \%$ Betadine solution onto $6 \mathrm{~mm}$ diameter BBL blank paper discs. In the Ag-gel studies, $50 \mathrm{mg}$ of Ag-gel was applied over 
the entire discs. In the Betadine and Ag-gel combination studies, $50 \mathrm{mg}$ of Ag-gel was applied over discs containing 20ul of Betadine. Three discs were distributed evenly onto the LB Agar surface. Following incubation, each disc piece was transferred to a sterile $1.5-\mathrm{mL}$ micro centrifuge tube containing $1 \mathrm{~mL}$ of PBS $(\mathrm{pH}=7.4)$ for enumeration of bacteria. The tubes were placed in a water bath sonicator for $10 \mathrm{~min}$ to loosen the cells within the disc and then vigorously vortexed 3 times for $1 \mathrm{~min}$ to detach the cells. Suspended cells were serially diluted (10-fold) in PBS, and 10- $\mu \mathrm{L}$ aliquots of each dilution were spotted onto LB Agar plates. In addition, the remained $900 \mu \mathrm{L}$ zero dilution sample was also plated on a different LB Agar plate. Thus, the equation for back calculating the bacterial concentration was CFU $\times$ dilution factor / inoculum size in $\mathrm{mL}$. This means that if only one bacterial cell was originally in the tube we would have a $90 \%$ chance of detecting it. All experiments were repeated three times with 3 discs each time. Thus, there were 9 separate determinations for each combination tested.

\section{Confocal laser scanning microscopy (CLSM)}

This was prepared as described above in CFU assay. Following the growth of the bacteria on the discs with and without antimicrobial material, some of the discs were removed for the CLSM study. The discs from the $S$. aureus GFP AH133/pCM11 and P. aeruginosa GFP PAO1/pMRP9-1 plates were examined under the Confocal Laser Scanning Microscopy (CLSM). S. aureus GFP and Pseudomonas aeruginosa GFP are lab strains which constitutively express green fluorescent protein from plasmids pCM11 or pMRP9-1 when grown in the presence of $1 \mu \mathrm{g} / \mathrm{ml}$ erythromycin or $300 \mu \mathrm{g} / \mathrm{ml}$ carbenicillin respectively. Three discs for each plate were examined for the presence of bacteria remaining on the discs by the confocal laser scanning microscopy (CLSM). Visualization of the $S$. aureus GFP AH133 and P. aeruginosa PAO1 GFP bacteria was accomplished with a Nikon Eclipse Ti upright confocal laser scanning microscope (Nikon, Melville, NY, USA). Samples were examined under 10X objective lens, FITC fluorescence laser (488.0 nm), 4 channel confocal, and 512 scan size. The images were processed and analyzed using NIS-Elements AR Imaging Software as previously described (Tran et al., 2013). All experiments were done in triplicate, and all measurements were repeated three times.

\section{Statistical Analyses}

Results of the CFU assays were statistically analyzed using GraphPad InStat 3.06 (GraphPad Software, San Diego, CA, USA). Significance between pairs of values (Control versus one treatment group) was calculated using an unpaired two-tailed t test when SD was not significantly different and when a Gaussian distribution was observed. If SD was significantly different, the Welch correction was applied to the unpaired two-tailed $t$ test. When non-Gaussian distribution was observed (Kolmogorov- Smirnov test), significance was calculated by a non-parametric Mann-Whitney test. Two treatment groups were compared using the Kruskal-Wallis test (non-parametric ANOVA) with Tukey's multiple comparisons test for significance. Differences were considered significant when the P-value was $<0.05$.

\section{Results}

\section{Effect of $5 \%$ Betadine treatment on bacterial biofilm formation for in vitro CFU studies}

The results for the 24 hour in vitro CFU studies in the presence of Betadine using Staphylococcus aureus GFP strain AH133 and Pseudomonas aeruginosa PAO1 GFP strain MM294, and clinical isolates of Klebsiella pneumoniae (K. pneumoniae CI), Staphylococcus epidermidis (S. epidermidis CI), and Methicillinresistant Staphylococcus aureus (MRSA CI) are illustrated in Figure 1 (A, B, C) and Figure 2 (A,B). The 5\% Betadine in the placebo gel showed at best approximately one log of inhibition of growth for Staphylococcus aureus GFP strain AH133, and clinical isolates of $K$. pneumoniae CI, S. epidermidis CI), and MRSA CI. However, 5\% Betadine showed little or no inhibition of Pseudomonas aeruginosa PAO1 GFP strain MM294. 


\section{Effect of Ag-gel treatment on bacterial biofilm formation for in vitro CFU studies}

The results for the 24 hour in vitro CFU studies in the presence of Ag-gel using Staphylococcus aureus GFP strain AH133 and Pseudomonas aeruginosa PAO1 GFP strain MM294, and clinical isolates of $K$. pneumoniae CI, S. epidermidis CI, and MRSA CI are illustrated in Figure 1 (A, B, C) and Figure 2 (A,B). As seen, the Ag-gel by itself showed inhibition of over 7 logs of the bacterial growth (100\%) in each case when compared to the untreated samples and to the placebo gel, which did not contain $\mathrm{Ag}$, with all the bacterial strains except $K$. pneumoniae. With $K$. pneumoniae (Figure 2 B) it only showed approximately 5 logs of inhibition when compared to the placebo gel. These results are in distinct contrast to those of $5 \%$ Betadine above.

Effect of the combination of $5 \%$ Betadine and Ag-gel treatment on bacterial biofilm formation for in vitro CFU studies

The results for the 24 hour in vitro CFU studies in the presence of the combination of 5\% Betadine and Ag-gel using Staphylococcus aureus GFP strain AH133 and Pseudomonas aeruginosa PAO1 GFP strain MM294, and clinical isolates of K. pneumoniae CI, S. epidermidis CI, and MRSA CI are illustrated in Figure $1(\mathrm{~A}, \mathrm{~B}, \mathrm{C})$ and Figure $2(\mathrm{~A}, \mathrm{~B})$. The difference between these results and those of either the 5\% Betadine alone and the Ag-gel alone, are that the combination of the two antimicrobials showed compete (100\%) inhibition to all the bacteria tested.

Effect of $5 \%$ Betadine, Ag-gel, and the combination of $5 \%$ Betadine and Ag-gel treatments on bacterial biofilm formation from in vitro Confocal laser scanning microscopy (CLSM) studies

To confirm the results of the previous experiments, the biofilm formation by Staphylococcus aureus GFP strain AH133 and Pseudomonas aeruginosa PAO1 GFP strain MM294 strains was studied on cellulose discs CLSM. The bacterial strains, were inoculated onto the discs in the same manner as for the CFU biofilm assay. Untreated discs were coated with placebo gel only. As above the discs were incubated for 24 hour $37^{\circ} \mathrm{C}$. As seen in Figures 3 and 4, S. aureus and P. aeruginosa, formed typical biofilms characterized by the presence of significant biofilm formation on the cellulose discs receiving no treatment, treated with the placebo gel or with 5\% Betadine alone. However, no bacteria or biofilm were seen on the cellulose discs treated with Ag-gel. These results confirm those obtained with the CFU assay.

\subsection{Figures}


A

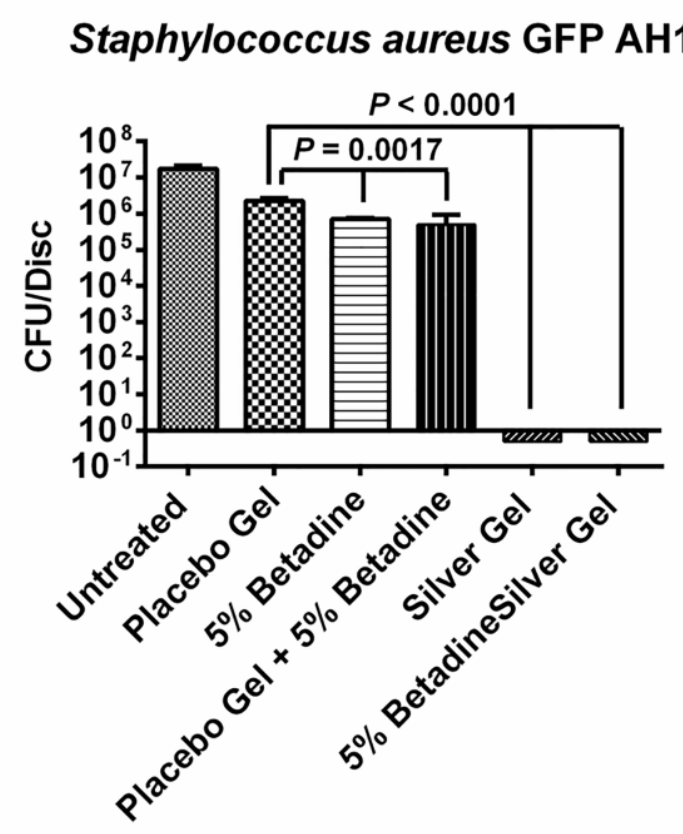

C

\section{Staphylococcus epidermidis $\mathrm{CI}$}

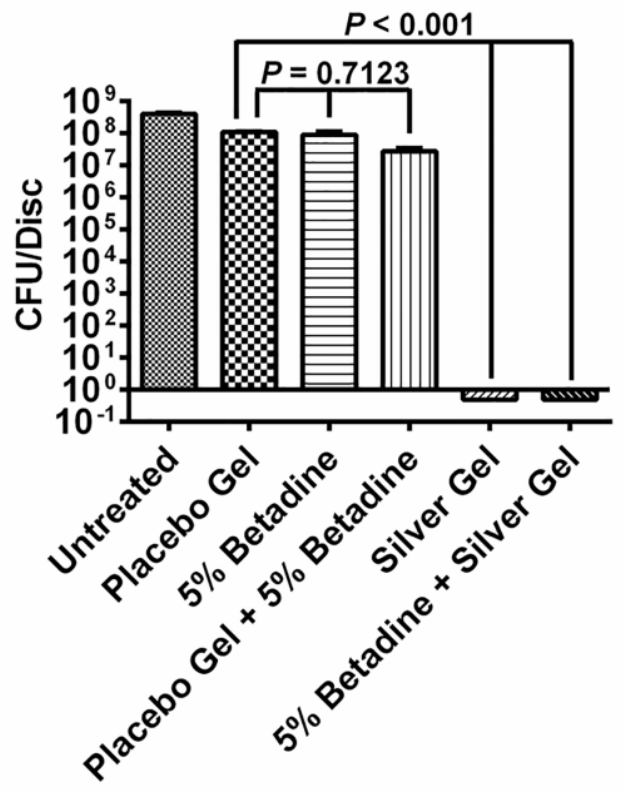

B

Methicillin-Resistant Staphylococcus aureus $\mathrm{Cl}$

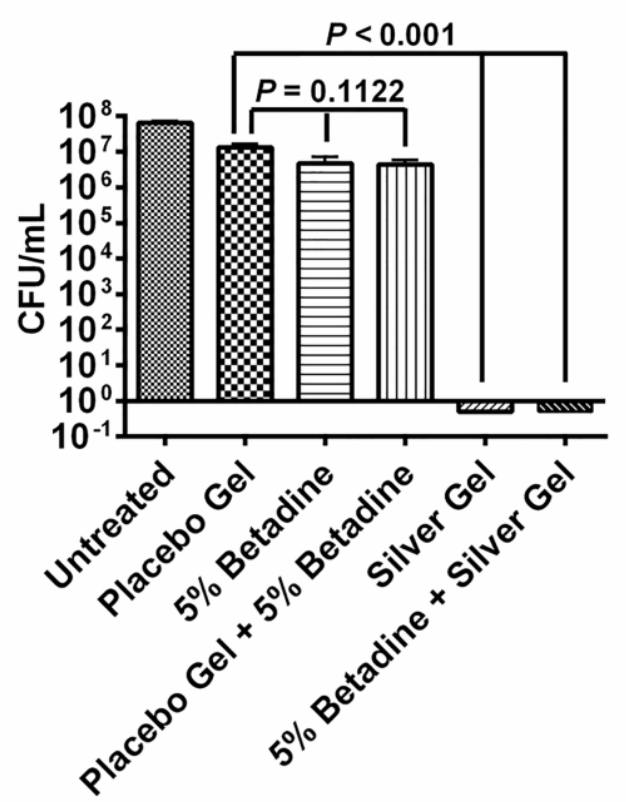

Figure 1.

The CFU results for the Gram positive bacteria, S. aureus GFP AH133 (A) MRSA CI (B), and S. epidermidis (C), on cellulose discs. The treatments were, none, placebo gel alone, placebo gel plus 5\% Betadine, Ag-gel, and a combination of the $5 \%$ Betadine and Ag-gel. Results were after 24 hours at $37^{\circ} \mathrm{C}$. All experiments were done at least in triplicate and were repeated three times. 


\section{A Pseudomonas aeruginosa PAO1 GFP}

B

Klebsiella pneumoniae $\mathrm{Cl}$
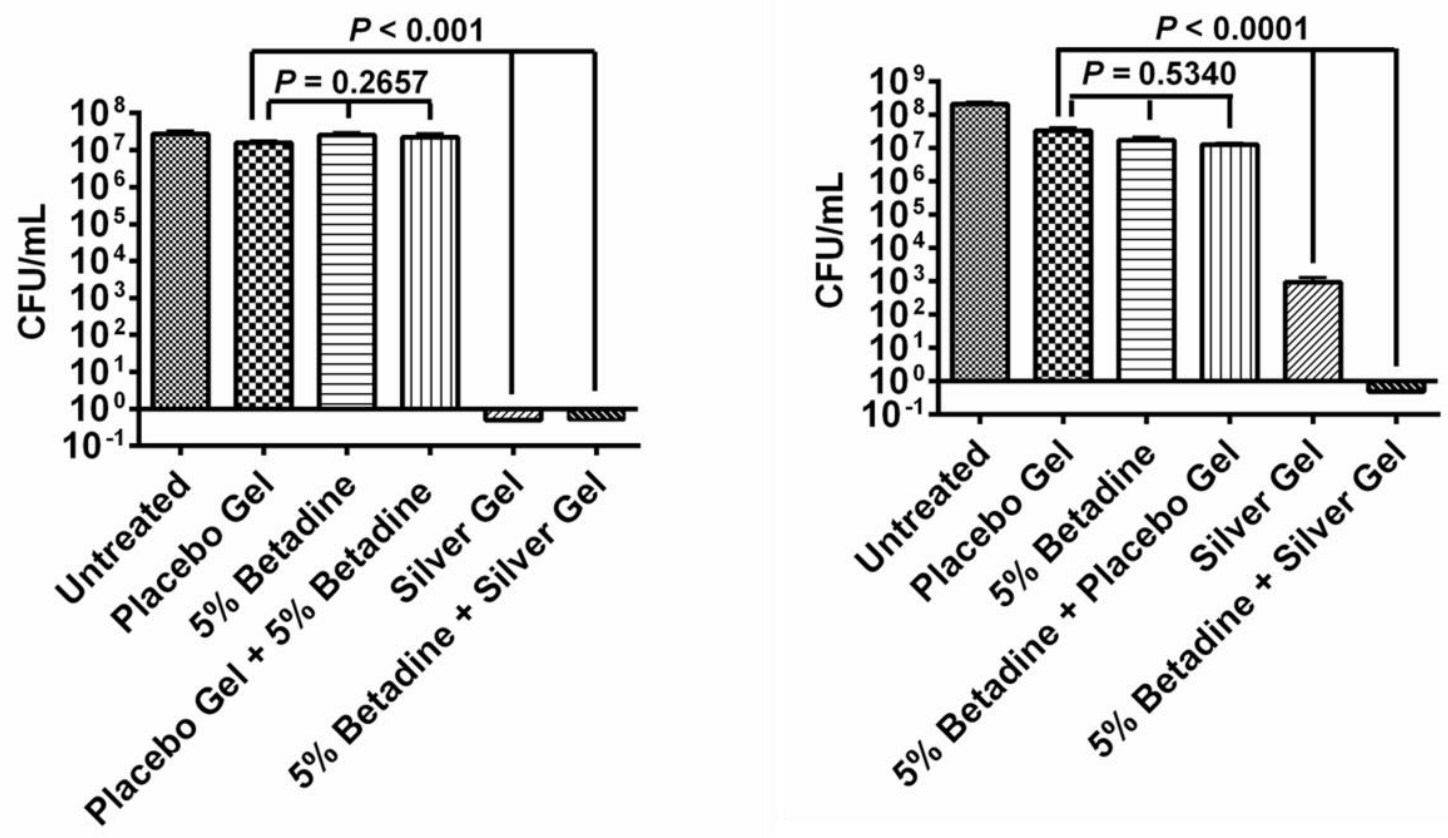

Figure 2.

The CFU results for the Gram negative bacteria, P. aeruginosa PAO1 GFP (A) K. pneumoniae CI (B) on cellulose discs. The treatments were, none, placebo gel alone, placebo gel plus 5\% Betadine, Ag-gel, and a combination of the $5 \%$ Betadine and Ag-gel. Results were after 24 hours at $37^{\circ} \mathrm{C}$. All experiments were done at least in triplicate and were repeated three times. 


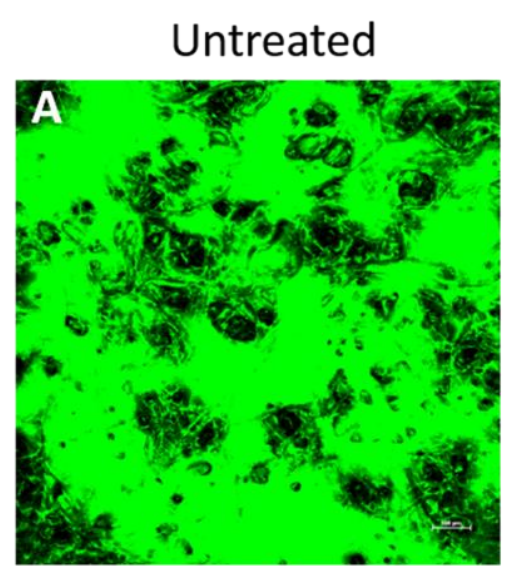

Placebo Gel + $5 \%$ Betadine

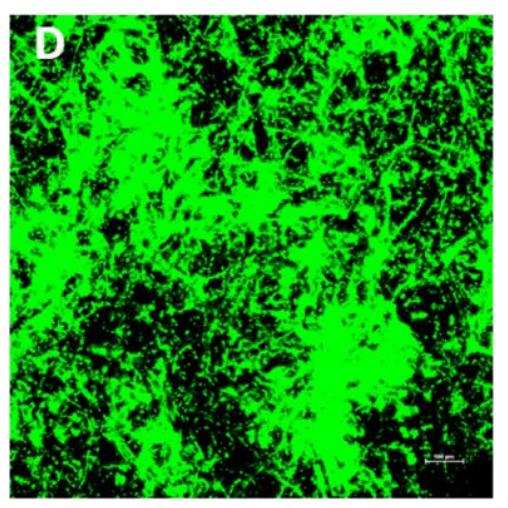

Placebo Gel

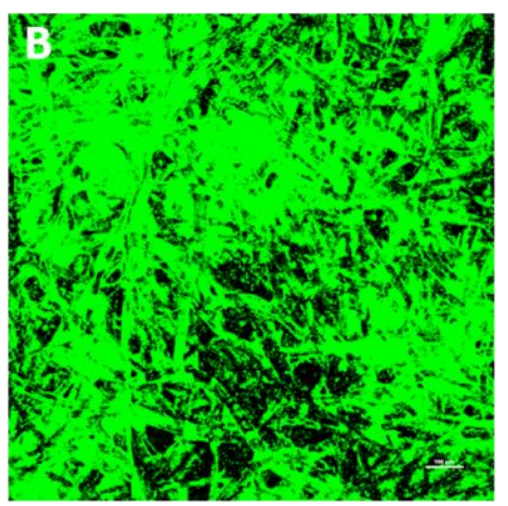

Silver Gel

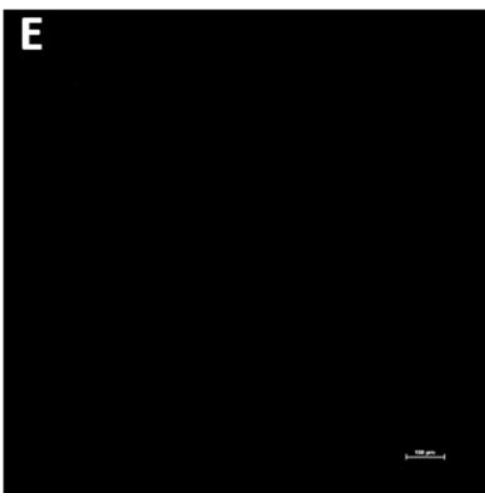

$5 \%$ Betadine

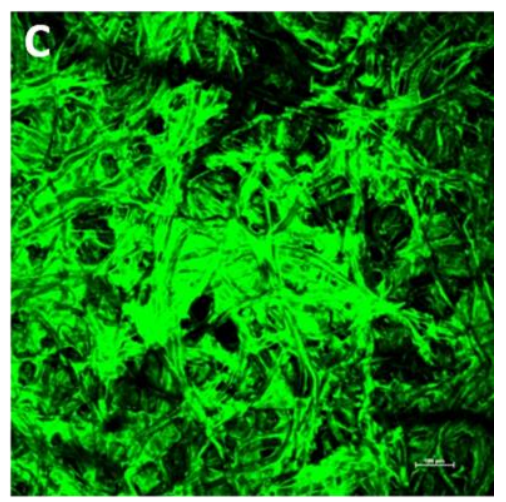

$5 \%$ Betadine

+ Silver Gel

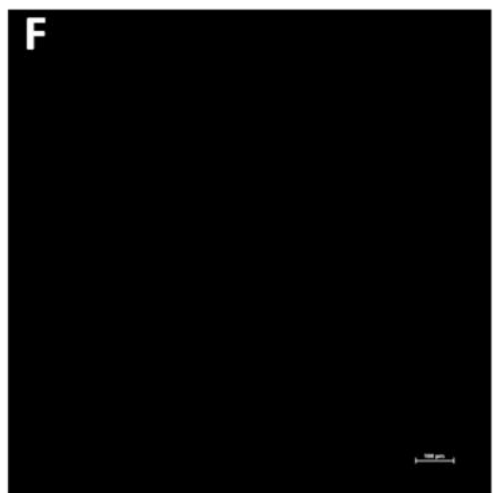

\section{Figure 3.}

Representative visualization with a Nikon Eclipse Ti upright confocal laser scanning microscope of S. aureus GFP AH133 (A, B, C, D, E, F), remaining on cellulose discs after 24 hours at $37^{\circ} \mathrm{C}$ in LB medium. The treatments were, none, placebo gel alone, placebo gel plus 5\% Betadine, Ag-gel, and a combination of the 5\% Betadine and Ag-gel. The images were processed and analyzed using NIS-Elements AR Imaging Software as previously described. Bar scale equals $100 \mu \mathrm{m}$. 


\section{Untreated}

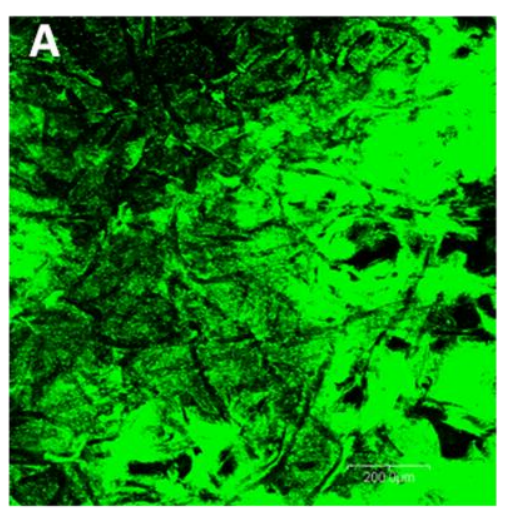

Placebo Gel + $5 \%$ Betadine

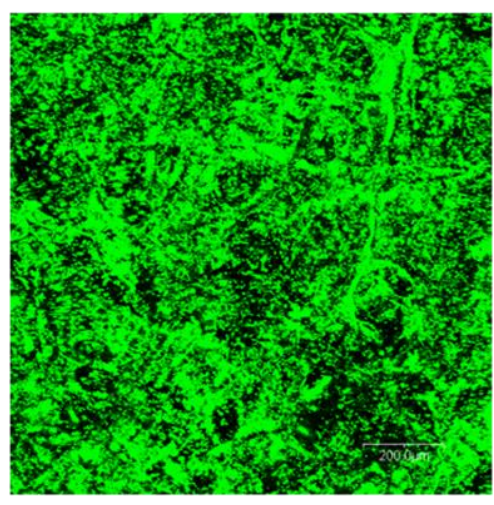

Placebo Gel

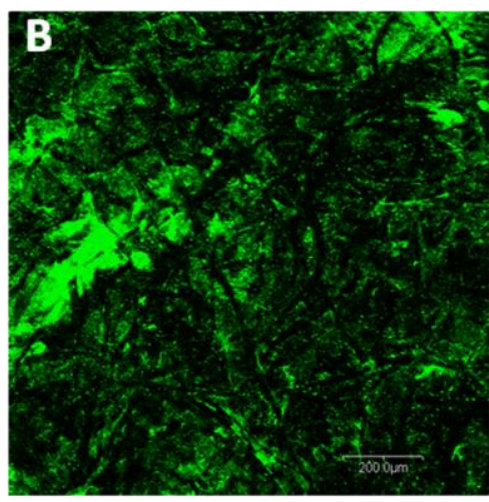

Silver Gel

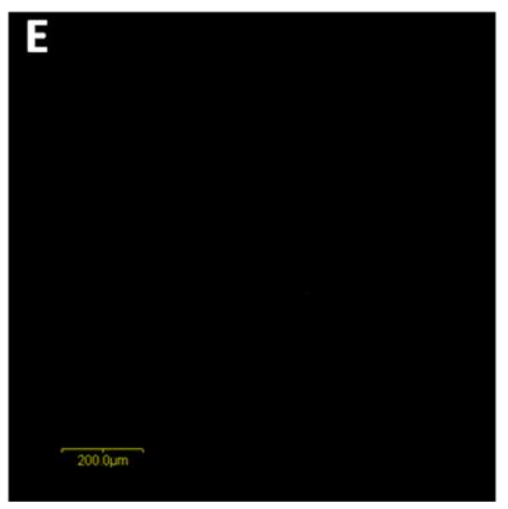

$5 \%$ Betadine

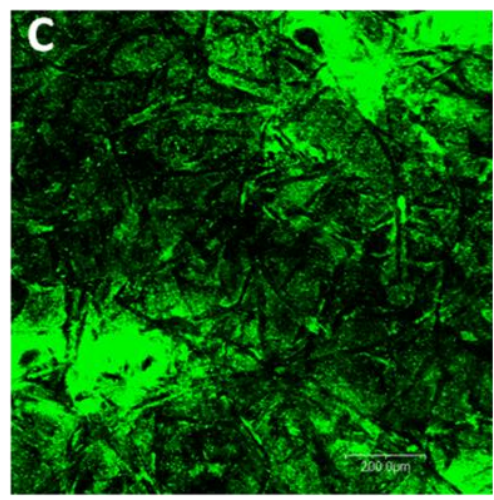

\section{$5 \%$ Betadine}

+ Silver Gel

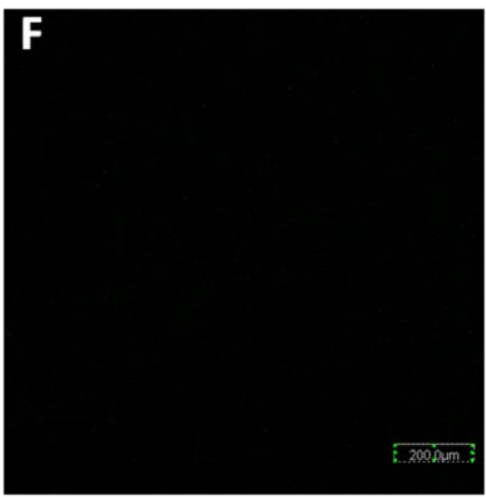

\section{Figure 4.}

Representative visualization with a Nikon Eclipse Ti upright confocal laser scanning microscope of $P$. aeruginosa PAO1 GFP (A, B, C, D, E, F), remaining on cellulose discs after 24 hours at $37^{\circ} \mathrm{C}$ in LB medium. The treatments were, none, placebo gel alone, placebo gel plus 5\% Betadine, Ag-gel, and a combination of the 5\% Betadine and Ag-gel. The images were processed and analyzed using NIS-Elements AR Imaging Software as previously described. Bar scale equals $200 \mu \mathrm{m}$. 


\section{Discussion}

Betadine is a widely used antiseptic because it has particularly broad spectrum of antimicrobial activity that includes Gram-positive and Gram-negative bacteria, bacterial spores, fungi, protozoa and viruses [8,12,14,26-29]. However, many studies have shown the inefficacy of Betadine solution against different bacteria [30-37]. Anderson et al., have documented the prolonged survival of Burkholderia cepacia in commercially manufactured providone-iodine [35]. In addition, there are several other studies have documented intrinsic contamination of a povidone-iodine solution led to both infections and pseudoinfections [31-34]. Cadexomer iodine (Iodosorb, or Iodoflex) is an effective form of iodine, however, since it is in a paste, ointment or gel form, we used Betadine as it would mix easier with our Ag-gel.

Our results, as seen in Figures 1-4, confirm that Betadine is very poor at inhibiting biofilm formation on cellulose pads in vitro. At best Betadine showed one log of inhibition of biofilm formation in in vitro CFU and confocal laser scanning microscope studies, and in the case of $P$. aeruginosa, it did not appear to show any inhibition.

We also tested silver because it appears to use a different killing mechanism from Betadine. It is believed that the killing mechanism is due to the binding of silver ions to bacterial proteins causing structural changes in the bacterial cellular membrane [19]. Silver ions also can bind and denature DNA and RNA, inhibiting bacterial replication [15, 18, 19, 38-41]. Silver is biologically active when it is soluble which is the $\mathrm{Ag}^{+}$and $\mathrm{Ag}^{\circ}$ forms. $\mathrm{Ag}^{\mathrm{o}}$ is the form present in nanocrystalline silver [41]. A comparison of silver ions versus nanocrystalline silver was carried out by Wright et al., (1998) [18]. They found that the nanocrystalline form was more efficacious than the ionic one. The use of nanocrystalline silver dressing has been recently reviewed by Fong \& Wood (2006) [15].

We found that Ag-gel is fairly effective in inhibiting bacteria from forming biofilms on cellulose. As seen above (Figures 1-4), the Ag-gel was $100 \%$ effective in blocking bacterial attachment of Staphylococcus aureus GFP strain AH133 Pseudomonas aeruginosa PAO1 GFP strain MM294, and clinical isolates of $S$. epidermidis CI, and MRSA CI. However, it only showed approximately 5 logs of inhibition of $K$. pneumoniae $\mathrm{CI}$ in a similar assay.

The reason that we feel that 5\% Betadine uses a different killing mechanism from silver, is that while $5 \%$ Betadine only showed approximately one log of killing of $K$. pneumoniae CI, it was synergistic with the Ag-gel in killing this bacteria. The combination resulted in $100 \%$ killing (over 7 logs) when compared to the placebo gel. It would thus appear that the combination of these two different topical antimicrobials would be a much more effective topical treatment for use in bacterial control.

A limitation to the current study is that the experiments were performed on biofilm bacteria, but the biofilm was formed from a single bacterial species. Biofilms formed from more than one species of bacterial may be harder to kill.

\section{Conclusions}

The results demonstrate that $5 \%$ Betadine is not an effective treatment for the prevention of bacterial biofilms grown on a cellulose sponge. A colloidal Ag-gel, however, appears to work quite well for most bacteria. In contrast, $5 \%$ Betadine was synergistic with Ag-gel in the prevention of growth of K. pneumoniae CI biofilms. Thus, the combination would appear to be a better treatment for topical biofilm control.

\section{References}

1. Church D, Elsayed S, Reid O, Winston B, Lindsay R. 2006. Burn wound infections. Clin Microbiol Rev 19:403-434. 
2. Lipsky BA, Berendt AR, Deery HG, Embil JM, Joseph WS, Karchmer AW, LeFrock JL, Lew DP, Mader JT, Norden C, Tan JS. 2004. Diagnosis and treatment of diabetic foot infections. Clin Infect Dis 39:885-910.

3. Markogiannakis H, Pachylaki N, Samara E, Kalderi M, Minettou M, Toutouza M, Toutouzas KG, Theodorou D, Katsaragakis S. 2009. Infections in a surgical intensive care unit of a university hospital in Greece. Int J Infect Dis 13:145-153.

4. Murray CK. 2008. Infectious disease complications of combat-related injuries. Crit Care Med 36:S358-364.

5. $\quad$ Burks RI. 1998. Povidone-iodine solution in wound treatment. Phys Ther 78:212-218.

6. Darouiche RO, Wall MJ, Jr., Itani KM, Otterson MF, Webb AL, Carrick MM, Miller HJ, Awad SS, Crosby CT, Mosier MC, Alsharif A, Berger DH. 2010. Chlorhexidine-Alcohol versus Povidone-Iodine for Surgical-Site Antisepsis. N Engl J Med 362:18-26.

7. Dumville JC, McFarlane E, Edwards P, Lipp A, Holmes A. 2013. Preoperative skin antiseptics for preventing surgical wound infections after clean surgery. Cochrane Database Syst Rev 3:Cd003949.

8. Fleischer W, Reimer K. 1997. Povidone-iodine in antisepsis--state of the art. Dermatology 195 Suppl 2:3-9.

9. Jeng DK, Severin JE. 1998. Povidone iodine gel alcohol: a 30-second, onetime application preoperative skin preparation. Am J Infect Control 26:488-494.

10. Hemani ML, Lepor H. 2009. Skin Preparation for the Prevention of Surgical Site Infection: Which Agent Is Best? Reviews in Urology 11:190-195.

11. Lepor NE, Madyoon H. 2009. Antiseptic skin agents for percutaneous procedures. Rev Cardiovasc Med 10:187-193.

12. Moshfeghi AA, Rosenfeld PJ, Flynn HW, Jr., Schwartz SG, Davis JL, Murray TG, Smiddy WE, Berrocal AM, Dubovy SR, Lee WH, Albini TA, Lalwani GA, Kovach JL, Puliafito CA. 2011. Endophthalmitis after intravitreal vascular [corrected] endothelial growth factor antagonists: a six-year experience at a university referral center. Retina 31:662-668.

13. Ferguson AW, Scott JA, McGavigan J, Elton RA, McLean J, Schmidt U, Kelkar R, Dhillon B. 2003. Comparison of $5 \%$ povidone-iodine solution against $1 \%$ povidone-iodine solution in preoperative cataract surgery antisepsis: a prospective randomised double blind study. Br J Ophthalmol 87:163-167.

14. Reichman DE, Greenberg JA. 2009. Reducing Surgical Site Infections: A Review. Reviews in Obstetrics and Gynecology 2:212-221.

15. Fong J, Wood F. 2006. Nanocrystalline silver dressings in wound management: a review. International Journal of Nanomedicine 1:441-449.

16. Barnea Y, Weiss J, Gur E. 2010. A review of the applications of the hydrofiber dressing with silver (Aquacel $\operatorname{Ag}\left({ }^{\circledR}\right)$ in wound care. Therapeutics and Clinical Risk Management 6:21-27.

17. Tredget EE, Shankowsky HA, Groeneveld A, Burrell R. 1998. A matched-pair, randomized study evaluating the efficacy and safety of Acticoat silver-coated dressing for the treatment of burn wounds. J Burn Care Rehabil 19:531-537.

18. Wright JB, Lam K, Burrell RE. 1998. Wound management in an era of increasing bacterial antibiotic resistance: a role for topical silver treatment. Am J Infect Control 26:572-577.

19. Yin HQ, Langford R, Burrell RE. 1999. Comparative evaluation of the antimicrobial activity of ACTICOAT antimicrobial barrier dressing. J Burn Care Rehabil 20:195-200. 
20. Malone CL, Boles BR, Lauderdale KJ, Thoendel M, Kavanaugh JS, Horswill AR. 2009. Fluorescent reporters for Staphylococcus aureus. J Microbiol Methods 77:251-260.

21. Holloway BW, Krishnapillai V, Morgan AF. 1979. Chromosomal genetics of Pseudomonas. Microbiological Reviews 43:73-102.

22. Tran P, Hamood A, Mosley T, Gray T, Jarvis C, Webster D, Amaechi B, Enos T, Reid T. 2013. Organo-selenium-containing dental sealant inhibits bacterial biofilm. J Dent Res 92:461-466.

23. Clinical and Laboratory Standards Institute. 2007. Methods for antimicrobial susceptibility testing of anaerobic bacteria. Approved standard, 7th ed. CLSI document M11-A7. Clinical and Laboratory Standards Institute, Wayne, PA.

24. Clinical and Laboratory Standards Institute. 2009. Performance standards for antimicrobial disc susceptibility tests. Approved standard, 10th ed. CLSI publication M02-A10. Clinical and Laboratory Standards Institute, Wayne, PA.

25. Clinical and Laboratory Standards Institute. 2011. Performance standards for antimicrobial susceptibility testing, 21st informational supplement. CLSI document M100-S21. Clinical and Laboratory Standards Institute, Wayne, PA.

26. Sriwilaijaroen N, Wilairat P, Hiramatsu H, Takahashi T, Suzuki T, Ito M, Ito Y, Tashiro M, Suzuki Y. 2009. Mechanisms of the action of povidone-iodine against human and avian influenza A viruses: its effects on hemagglutination and sialidase activities. Virol J 6:124.

27. McDonnell G, Russell AD. 1999. Antiseptics and Disinfectants: Activity, Action, and Resistance. Clinical Microbiology Reviews 12:147-179.

28. Kanagalingam J, Feliciano R, Hah JH, Labib H, Le TA, Lin JC. 2015. Practical use of povidone-iodine antiseptic in the maintenance of oral health and in the prevention and treatment of common oropharyngeal infections. Int J Clin Pract 69:1247-1256.

29. Manna VK, Pearse AD, Marks R. 1984. The effect of povidone-iodine paint on fungal infection. J Int Med Res 12:121-123.

30. Weber DJ, Rutala WA, Sickbert-Bennett EE. 2007. Outbreaks associated with contaminated antiseptics and disinfectants. Antimicrob Agents Chemother 51:4217-4224.

31. Kaslow RA, Mackel DC, Mallison GF. 1976. Nosocomial pseudobacteremia. Positive blood cultures due to contaminated benzalkonium antiseptic. Jama 236:2407-2409.

32. Kahan A, Philippon A, Paul G, Weber S, Richard C, Hazebroucq G, Degeorges M. 1983. Nosocomial infections by chlorhexidine solution contaminated with Pseudomonas pickettii (Biovar VA-I). J Infect 7:256-263.

33. Jarvis WR. 1991. Nosocomial outbreaks: the Centers for Disease Control's Hospital Infections Program experience, 1980-1990. Epidemiology Branch, Hospital Infections Program. Am J Med 91:101s-106s.

34. Berkelman RL, Lewin S, Allen JR, Anderson RL, Budnick LD, Shapiro S, Friedman SM, Nicholas P, Holzman RS, Haley RW. 1981. Pseudobacteremia attributed to contamination of povidone-iodine with Pseudomonas cepacia. Ann Intern Med 95:32-36.

35. Anderson RL, Vess RW, Panlilio AL, Favero MS. 1990. Prolonged survival of Pseudomonas cepacia in commercially manufactured povidone-iodine. Appl Environ Microbiol 56:35983600.

36. Panlilio AL, Beck-Sague CM, Siegel JD, Anderson RL, Yetts SY, Clark NC, Duer PN, Thomassen KA, Vess RW, Hill BC, et al. 1992. Infections and pseudoinfections due to 
povidone-iodine solution contaminated with Pseudomonas cepacia. Clin Infect Dis 14:10781083.

37. Parrott PL, Terry PM, Whitworth EN, Frawley LW, Coble RS, Wachsmuth IK, McGowan JE, Jr. 1982. Pseudomonas aeruginosa peritonitis associated with contaminated poloxameriodine solution. Lancet 2:683-685.

38. Lansdown AB. 2002. Silver. I: Its antibacterial properties and mechanism of action. J Wound Care 11:125-130.

39. Thomas S, McCubbin P. 2003. A comparison of the antimicrobial effects of four silvercontaining dressings on three organisms. J Wound Care 12:101-107.

40. Hiro Matthew E, Pierpont Yvonne N, Ko F, Wright Terry E, Robson Martin C, Payne Wyatt G. 2012. Comparative Evaluation of Silver-Containing Antimicrobial Dressings on In Vitro and In Vivo Processes of Wound Healing. Eplasty 12:e48.

41. Dunn K, Edwards-Jones V. 2004. The role of Acticoat with nanocrystalline silver in the management of burns. Burns 30 Suppl 1:S1-9. 